\title{
The effect of using Non-Uniform Blank Holder Force in Deep Drawing process on the thickness distribution along the cup
}

\author{
Alaa Dahaam Younis \\ University of Mosul, Ninawa-Iraq, Feb.2012
}

\begin{abstract}
In this paper, a new concept of blank holder in deep drawing is presented. The aim of this study is to predict the wrinkling and thinning (necking) failure through the study of the effect of using constant, variable and non-uniform blank holder force $(\mathbf{B H F})$ between the blank and blank holder on the thickness distribution along the cup (wall, base and nose). Numerical modeling were carried out on various values of blank holder force (BHF) (i.e., Constant-Uniform, Variable-Uniform, Constant Non-Uniform and Variable Non-Uniform). The simulation results shows that the best value of blank holder force were achieved at Variable Non-Uniform type; which gives the smallest difference between maximum and minimum thickness distribution along the cup.
\end{abstract}

Key wards: ANSYS 11, Deep Drawing, Blank holder force

$$
\begin{aligned}
& \text { تأثير استخدام قوة مثبت الغفل الغير منتظمة التوزيع في عملية السحب العميق على نوزيع } \\
& \text { السمك على طول الكأس ملنع } \\
& \text { جامعة الموصل، العراقانينوى، شحباط } 2012 \\
& \text { الخلاصــــــة }
\end{aligned}
$$

قي هذا البحث تم در اسة مفهوم جديد لمثبت الغفل في عملية السحب العميق. الهدف من هذا الدر اسة هو التوقع للفتنل نتيجة

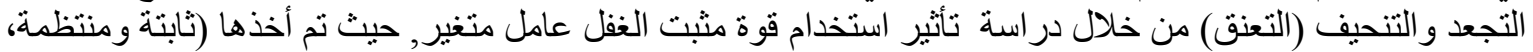

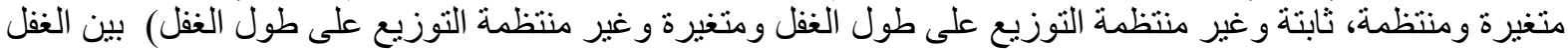

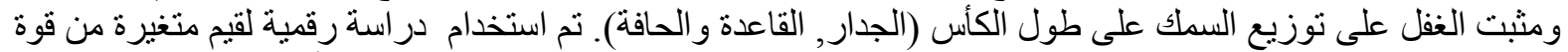

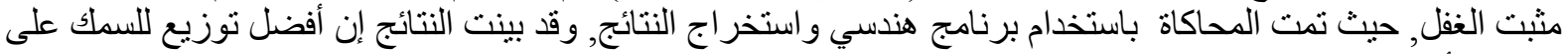
طول الكأس هو عند استخدام قوة مثبت الغفل المتغيرة والغير منتخمة التخد التوزيع على طول الغفل. 


\section{Introduction}

The quality of deep drawn products is highly dependent upon the rate at which the sheet is drawn into the die. It is necessary to optimize the restraining forces applied to the blank for a given blank shape, material and final part geometry. For non-symmetric parts that have non-uniform material properties, the optimization of the (BHF) requires that the pressure distribution on the blank be varied spatially and as a function of time or press ram position [1].

Excessive metal flow will cause wrinkles in the part while insufficient metal flow will result in tears or splits. The blank holder plays a key role in regulating the metal flow by exerting a predefined (BHF) profile. When selected properly, this (BHF) profile can eliminate wrinkles and delay fracture in the drawn part [2].

Usually, in deep drawing, a constant BHF is applied over the punch stroke. During the drawing process, the state of stress in the deforming material changes significantly. Consequently, the process conditions that reduce wrinkling and fracture also change. To take into account these changes, it is reasonable that the BHF should also be modified to increase the formability of the drawn part. To further improve the formability when drawing complex parts, an elastic or segmented blank holder can be used to obtain a non-uniform BHF over the part flange area. Thus, it is possible to account for variations of the blank holder surface [3]. The incentive for doing this research is that deep drawing has come to a stage in the current industrialized world that requires the most efficient, low-cost, manufacturing route to be taken at all times [4].

The general opinion in the automotive industry is that improvement may be achievable in some components by introducing a variable BHF [5]. The finite element analysis (FEA) and numerical simulations are usually carried out under the working conditions specified by the users. The users repeat the simulation by changing the conditions until an a acceptable result or an optimized one is reached. It may be possible to reduce users efforts by setting an appropriate condition during the numerical simulation [6].

\section{Blank holding}

Blank holding principally aims at preventing wrinkling. The two methods used for blank holding are [7-9]:

1. Clearance blank holding (fixed blank holding).

2. Pressure blank holding.

Clearance blank holding maintains a fixed clearance which may resist anticipated thickening at some stage of drawing. 5\% clearance is practically sufficient to resist wrinkling but does not avoid development of a stretching region.

Pressure blank holding can provide a varying blank holding force and at the same time restrain some of the thickening of the rim.

Blank holding force produces a frictional force resisting the radial movement towards the die orifice, thus increasing the load acting on the wall.

\section{Numerical Simulation Modeling}

In deep drawing, numerical simulations have been widely used to assist parts and process design by:

- Predicting the material flow during the particular process (on the die in deep drawing).

- Predicting the punch force, blank holder force and the stresses necessary to execute the forming process.

- Prevent the failure caused by the defect in tooling design. 
Solid elements, shell elements and membrane elements are three main types of finite elements that can be used in finite element modeling of the blank and tooling elements, the elements of the forming tools are usually intended to impose the forming loads to the sheet metal through the forming interface. Due to the fact that the forming tools should be, theoretically, designed to be rigid and the die-face deformations should be elastic with minimal shape changes, only the surface geometry of the forming tool are generally included in the process simulation [2].

In this work the commercial FEM code (ANSYS 11) are used to simulate the process of Nonuniform distribution of blank holder force in deep drawing operation. Cup forming was created and the numerical results were compared with the uniform distribution of blank holder force results. When placing the parts in the system, the direction and the values of wall thickness were taken into consideration. Mild steel sheet was used, with the mechanical properties, shown in table (1). Figure (1) Show the modeling system is composed of the press, blank holder, blank (sheet metal) and die. This cup without flange, and completely drawn into the die shown in figure (2) and (3).

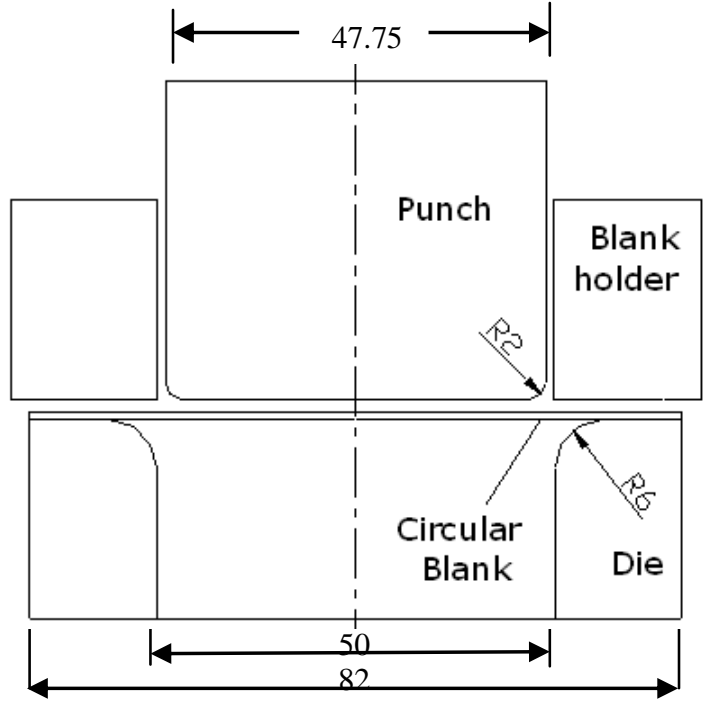

Figure (1) Geometry of the tools used in this study

The punch, die and the blank holder represented by element type (Target 169), which defined by three nodes having two degrees of freedom at each node. The blank material represented by element type (Visco 108), which defined by four nodes having up to three degrees of freedom at each node. The contact interface between die and the deformed material is represented by element type (Contact 171), which has two degrees of freedom at each node. Figure (4) shows the meshing for the model.

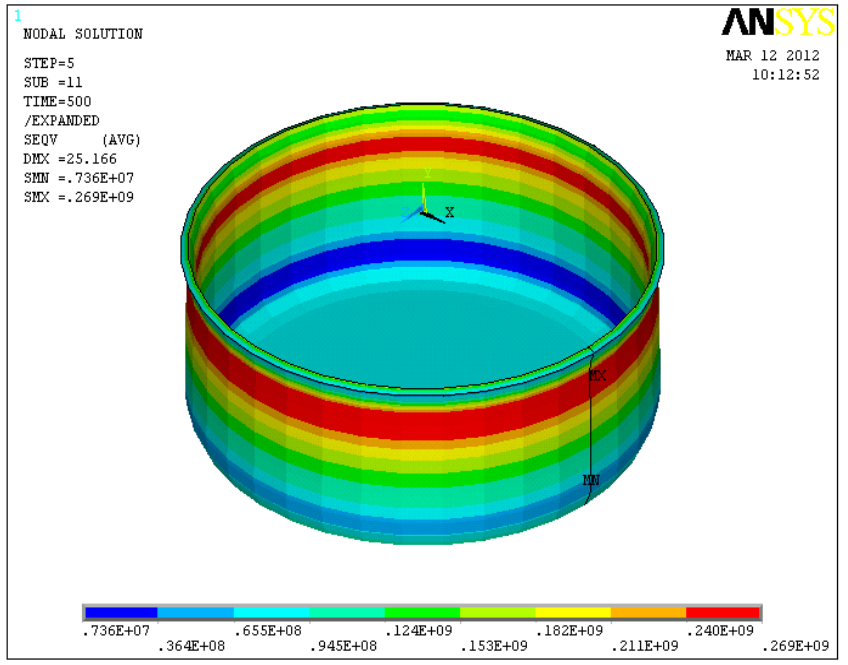

Figure (2) 360 2-D axisymmetric symmetry expansion of the deformed

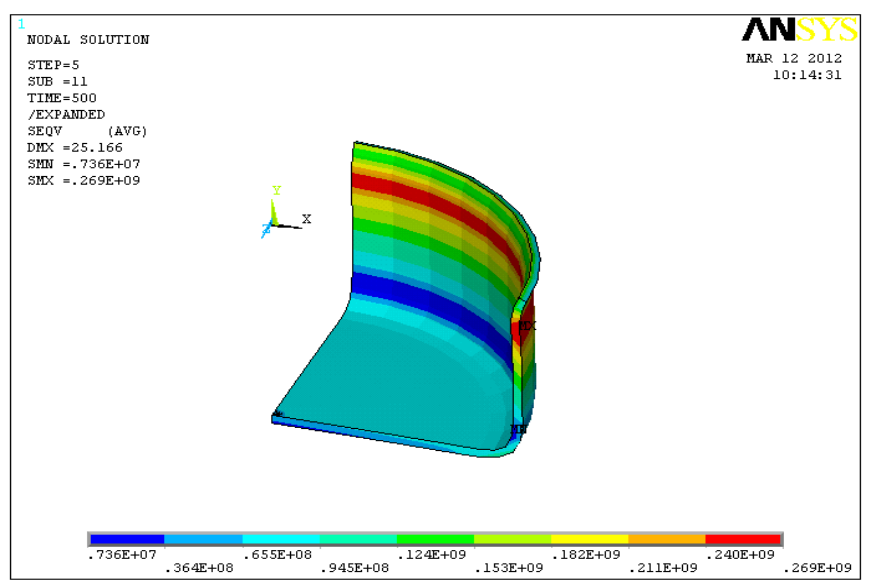

Figure (3) 90o 2-D axisymmetric symmetry expansion of the deformed cup 


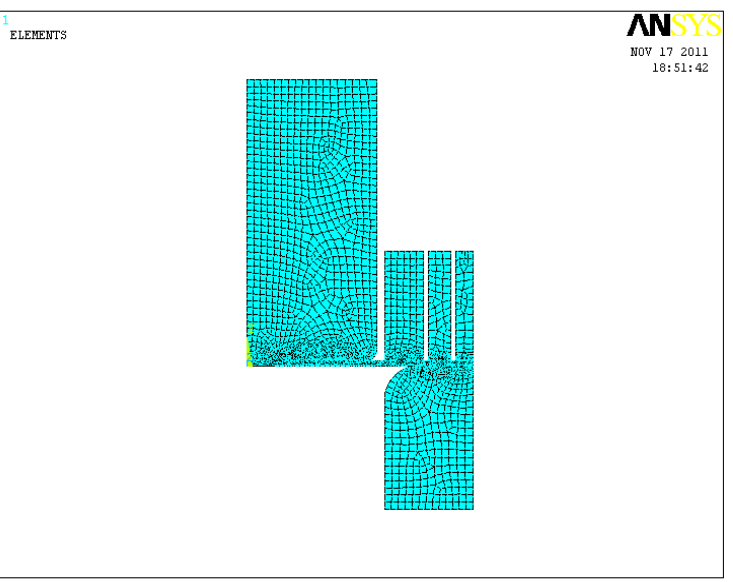

The loading was conducted in the form of a prescribed displacement. The total travel of punch was $(\mathrm{y}=40 \mathrm{~mm})$. Isotropic Hardening Plasticity model was used, the plastic response was modeled using the Von Mises Yield Criterion, with the material properties listed in Table-1-.

Figure (4) finite element model

Table -1- Mechanical Properties

\begin{tabular}{|c|c|c|c|c|c|}
\hline $\begin{array}{c}\text { Initial } \\
\text { Thickness } \\
\text { to }(\mathrm{mm})\end{array}$ & $\begin{array}{c}\text { Tangent Modulus of } \\
\text { Elasticity ET }(\mathrm{GPa})\end{array}$ & YS (MPa) & $\mathrm{E}(\mathrm{GPa})$ & Poisson's Ratio & $\begin{array}{c}\text { Coefficient of } \\
\text { Friction } \\
\mu\end{array}$ \\
\hline 1 & 0.5 & 190 & 200 & 0.3 & 0.05 \\
\hline
\end{tabular}

\section{Description of the types of Blank Holder Force}

1. Uniform-load constant (BHF). In constant $\mathrm{BHF}$ the force remains constant when the punch is moving down.

2. Uniform-load variable (BHF). The load is the same as distribution in figure (5) but the meaning of variable BHF is; the force increases (changes) during the punch is moving down.

3. Non-Uniform load constant (BHF). The NonUniform (BHF) (shown in figure 6). The BHF is remained constant during the Punch is moving down.

4. Non-uniform load variable (BHF).The load distribution is the same as in figure (6) and the BHF increases (Changes) during the punch moving down.
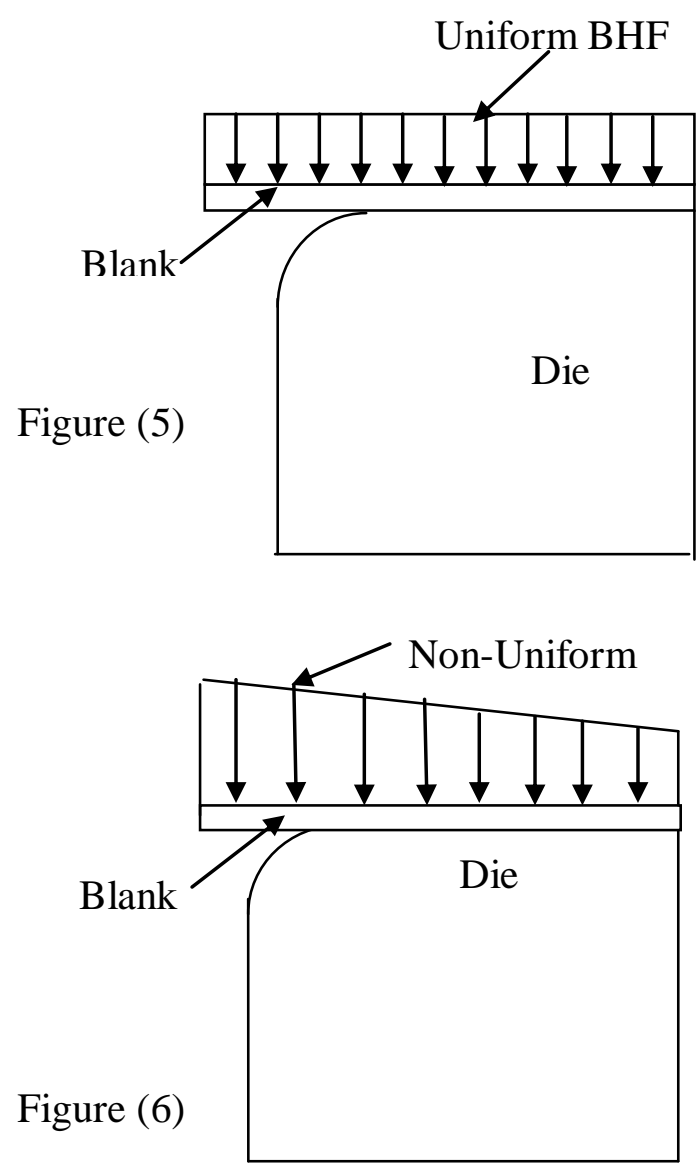


\section{Results and discussion}

In this paper, different blank holder forces were used by taking different cases, such as constant BHF(UC), variable BHF(UV), constant Non-Uniform BHF(NUC) and variable Non-Uniform BHF(NUV) (which listed in table -2-) and their effects have been explained and discussed during Deep Drawing process.

Table -2-Blank Holder Force Distribution

\begin{tabular}{|c|c|c|c|c|}
\hline & Term meaning & $\begin{array}{l}\text { Beginning of } \\
\text { flange(start of } \\
\text { edge die) }\end{array}$ & $\begin{array}{c}\text { middle of } \\
\text { flange(middle } \\
\text { of edge die) }\end{array}$ & $\begin{array}{c}\text { end of flange(end of } \\
\text { edge die) }\end{array}$ \\
\hline $\mathrm{UC}$ & $\begin{array}{l}\text { uniform distribution } \\
\text { constant blank holder } \\
\text { force along the flange }\end{array}$ & $100 \mathrm{KN}$ & $100 \mathrm{KN}$ & $100 \mathrm{KN}$ \\
\hline UV & $\begin{array}{l}\text { uniform distribution } \\
\text { variable blank holder } \\
\text { force along the flange }\end{array}$ & $\begin{array}{l}100-150-200- \\
250-300 \mathrm{KN}\end{array}$ & $\begin{array}{l}100-150-200- \\
250-300 \mathrm{KN}\end{array}$ & $\begin{array}{c}100-150-200-250- \\
300 \mathrm{KN}\end{array}$ \\
\hline NUC & $\begin{array}{l}\text { Non-uniform distribution } \\
\text { constant blank holder } \\
\text { force along the flange }\end{array}$ & $300 \mathrm{KN}$ & $150 \mathrm{KN}$ & $25 \mathrm{KN}$ \\
\hline NUV & $\begin{array}{l}\text { Non-uniform distribution } \\
\text { variable blank holder } \\
\text { force along the flange }\end{array}$ & $\begin{array}{l}100-150-200- \\
250-300 \mathrm{KN}\end{array}$ & $\begin{array}{l}50-100-150- \\
200 \mathrm{KN}\end{array}$ & $10-50-100 \mathrm{KN}$ \\
\hline
\end{tabular}

\subsection{The effect of BHF on (wall, base and nose) thicknesses}

The effect of BHF on the (wall, base and nose) thicknesses of mild steel sheet was examined in Figure.7. To investigate the effect of values of BHF on the deep drawing process, four values of BHF were chosen for the simulation of deep drawing operation.

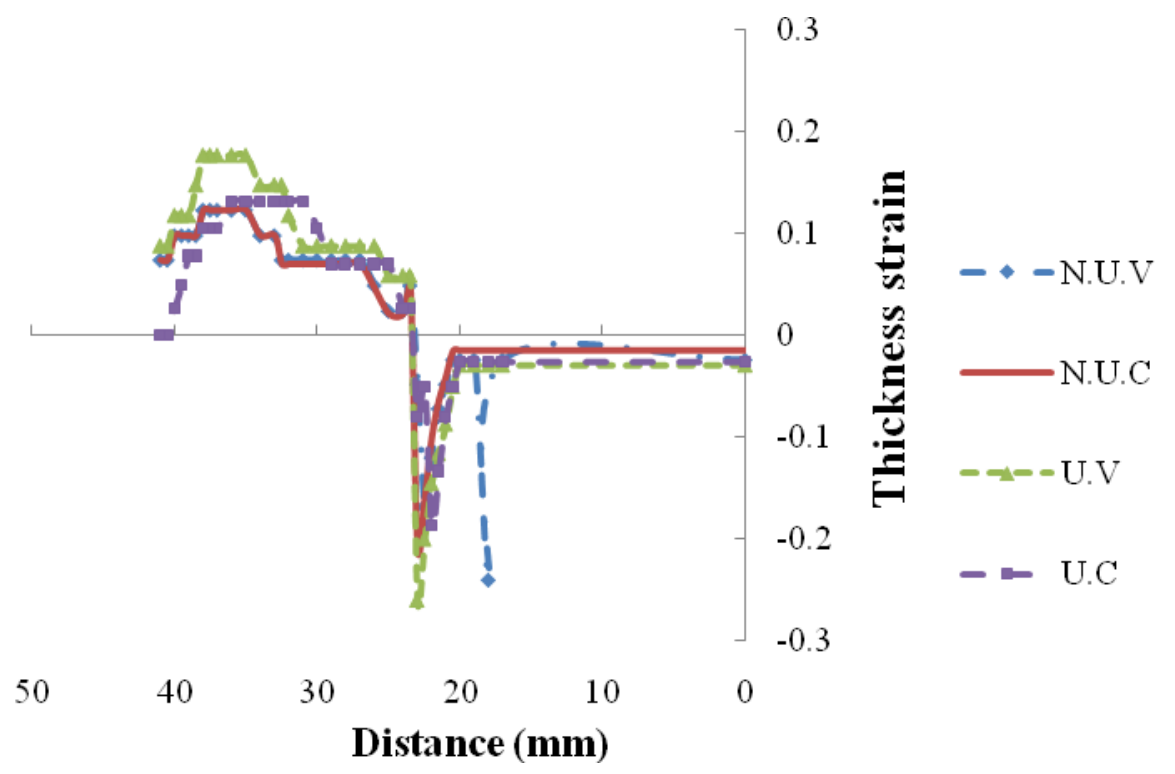

Figure (7) Thickness strain distribution along the cup 
Figure (7) shows the relationship between the thickness strain in the cup and the distance from cup center. The thickness approximately is constant under the punch base, and then increases on the cup wall until a maximum value obtained at the end of the cup wall. The hoop stress (circumference) tends to thicken the blank in the end of the cup wall. Both friction and stretch will occur over the punch nose, the blank thinning near the punch base. The lowest variation between the maximum and minimum thicknesses is found at Non-Uniform variable (NUV) BHF (i.e., 16.8\% thinning and 12.3\% thicking). The variation in Non-Uniform constant (NUC) BHF is $21 \%$ thinning and $9 \%$ thicking, for Uniform variable (UV) BHF is $26 \%$ thinning and $17.7 \%$ thicking and for Uniform constant (UC) BHF is $18.6 \%$ thinning and $13.1 \%$ thicking.

\subsection{The effect of BHF on effective strain}

Figure (8) shows the relationship between the effective strain and the distance from cup center, the difference in the effective strain is higher near the center radius (under punch) because of the equal biaxial tension and gradually decrease as moving further from the center until it reaches the end of the cup wall (i.e. where all curves are meeting at a single point).

The maximum thickness strain values were achieved with UV BHF and the minimum value with NUV BHF.

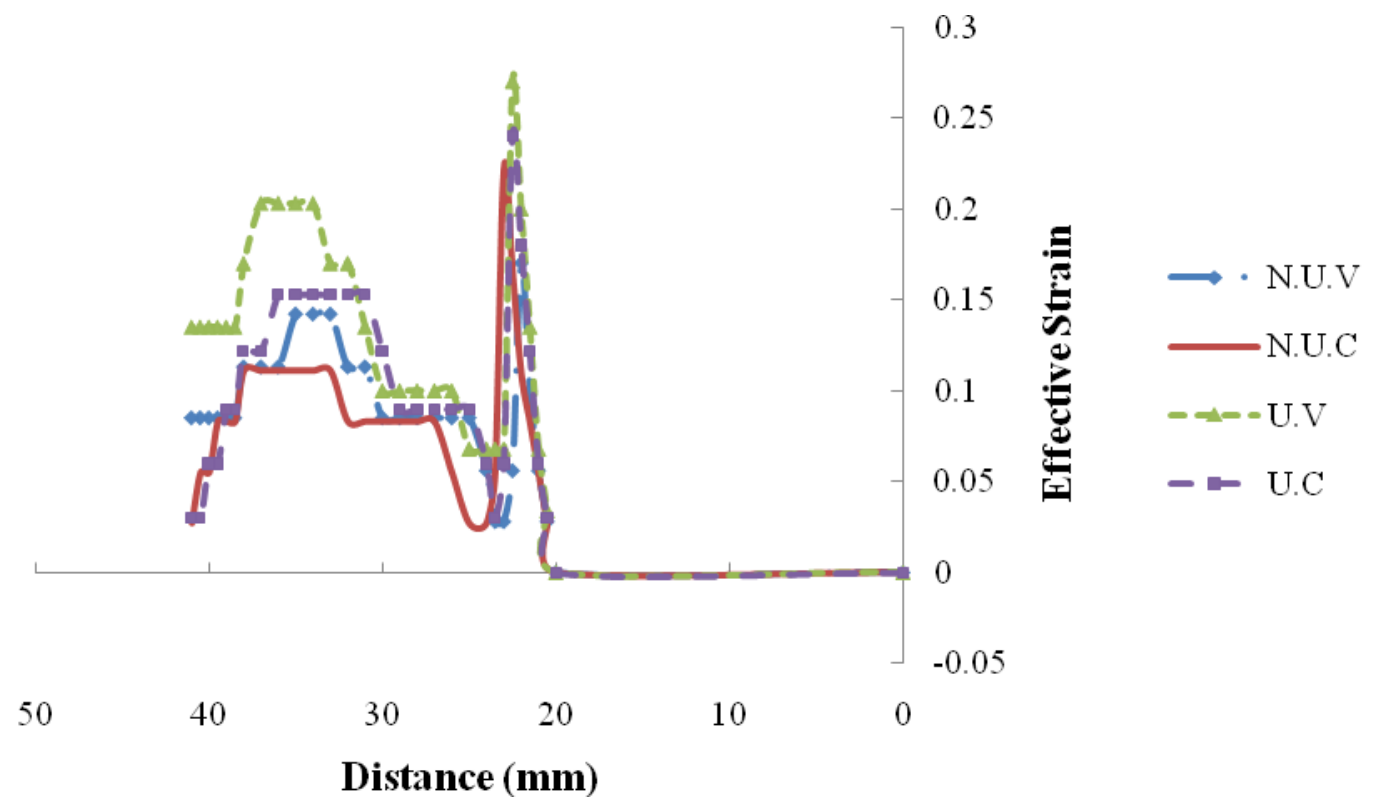

Figure (8) the effect of BHF on effective strain

\section{3 .The effect of BHF on effective stress}

Figure (9) shows the relationship between the effective stress and the distance from cup center, where the four cases of BHF are behaving uniformly and approximately similar. The effective stress has almost low constant value under the punch base because there is no forming under the punch base. The effective stress increase on the cup wall until it reaches the maximum at the end of the cup wall. 


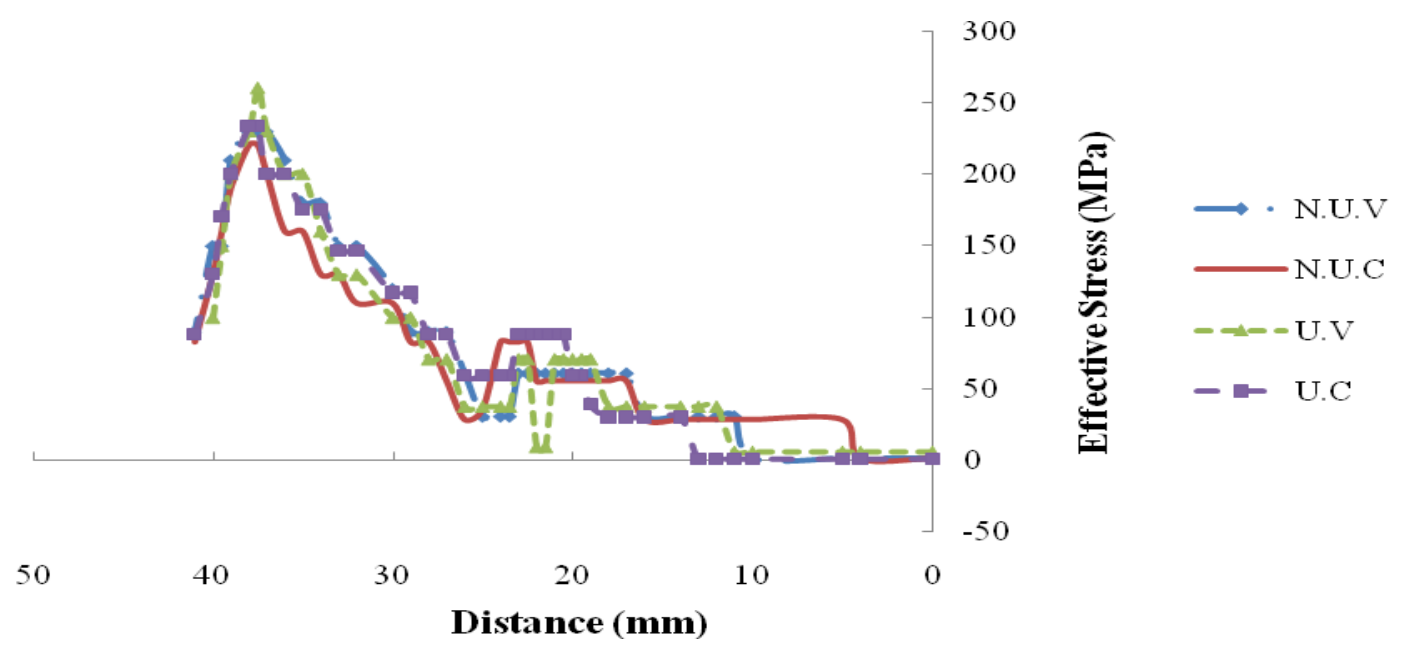

Figure (9) the effect of BHF on effective stress

\section{Conclusion}

Determination of an optimal BHF for producing a cup without defects in axi-symmetric deep drawing of steel sheet was studied though FEM simulations. It can be concluded that the simulation method can predict an optimum BHF for cup drawing process. The results show that the best BHF profile is Non-Uniform variable BHF, which can improve the uniformity of the cup thickness distribution in deep drawing.

\section{References}

1. Leonid B.Shulkin, Ronald A.Postraro, Mustafa A.Ahmetoglu, Gary L.Kinzel and Taylan Altan, Blank holder force control in viscous pressure forming (VPF) of sheet metal, Journal of materials processing Technology 98 (2000).

2. H.Ibrahim Demircii, Mustafa Yasar, Kemal Demiray and Mehmet Karah, The theoretical and experimental investigation of blank holder forces plate effect in deep drawing process of AL 1050 material, Materials and design 29 (2008).

3. Z.Q.Sheng, S.Jirathearanat and T.Altan, Adaptive FEM simulation for prediction of variable blank holder force in conical cup drawing, International Journal of machine Tools \& Manufacture 44 (2004).

4. NEVILLE LAWLESS, A finite-element analysis of the deep drawing process, School of Mechanical and Manufacturing engineering

Dublin City University, 2011.

5. Last Gunnarsson and Erik Schedin, Improving the properties of exterior body panels in automobiles using variable blank holder force, Journal and materials processing Technology 114 (2001).

6. Kozo Osakada, Chan Chin Wang and Ken-ichi Mori, Control FEM simulation for determining history of blank holder force in deep drawing, Osaka University, Japan-January 10 (1995).

7. Kurt Lange, Hand Book of metal forming, university of Stuttgart 1985.

8. Jamal Hematian, Finite element modeling of wrinkling during deep drawing of pressure vessel end closures, thesis at Queen`s University, Canada 2000.

9. Taylor Lyman, Metal hand book, $8^{\text {th }}$ edition, vol.4, forming, American society for metals, 1979, p. 162-195.

The work was carried out at the college of Engineering. University of Mosul 